\title{
Barriers to implementation of pediatric emergency department interventions for parental tobacco use and dependence: a qualitative study using the theoretical domains framework
}

\author{
Ashley L. Merianos ${ }^{1,2^{*}}$ (D, Kayleigh A. Fiser ${ }^{1}$, E. Melinda Mahabee-Gittens ${ }^{3}$, Michael S. Lyons ${ }^{2,4}$ and
} Judith S. Gordon ${ }^{5}$

\begin{abstract}
Background: Pediatric emergency department (PED) and urgent care (UC) professionals can play a key role in delivering evidence-based guidelines to address parental tobacco use and child tobacco smoke exposure (TSE). Understanding PED/UC professionals' perceptions regarding these guidelines is the first step in developing and implementing a TSE screening and counseling intervention in these settings. This study aimed to use the theoretical domains framework (TDF) to identify current screening and counseling behaviors of PED/UC professionals related to parental tobacco use and child TSE, and determine barriers and enablers that influence these behaviors.

Methods: Semi-structured, focused interviews were conducted with 29 actively practicing PED/UC clinical staff who worked at one large, Midwestern children's hospital. The interview guide was informed by the TDF and included open-ended questions. Content analysis of interview transcripts was guided by the TDF. Nurses, physicians, and healthcare administrators were assessed overall and by group membership to ensure each group was represented based on their varying PED/UC roles.

Results: Fifty-one percent were nurses, 38\% were physicians, and 11\% were healthcare administrators. Most PED/UC professionals did not currently follow the guidelines, but perceived addressing parental tobacco use as part of their role. All 14 TDF domains were identified by nurses, physicians, and administrators in relation to counseling for parental tobacco use and child TSE. Domains with the most sub-themes were (1) knowledge: lack of knowledge about tobacco counseling, including implementing counseling, cessation resources/referrals, and thirdhand smoke; (2) beliefs about capabilities: not comfortable counseling parents, easier to discuss with parents who are receptive and to ask and advise when patients have a TSE-related complaint, and more likely to discuss if there were resources/referrals; and (3) environmental context and resources: barriers include lack of time, training, and resources and referral information to give to parents, and an enabler is using TSE-related complaints as a context to offer counseling.
\end{abstract}

*Correspondence: ashley.merianos@uc.edu

1 School of Human Services, University of Cincinnati, P.O. Box 210068, Cincinnati, OH 45221-0068, USA

Full list of author information is available at the end of the article

(c) The Author(s) 2022. Open Access This article is licensed under a Creative Commons Attribution 4.0 International License, which permits use, sharing, adaptation, distribution and reproduction in any medium or format, as long as you give appropriate credit to the original author(s) and the source, provide a link to the Creative Commons licence, and indicate if changes were made. The images or other third party material in this article are included in the article's Creative Commons licence, unless indicated otherwise in a credit line to the material. If material is not included in the article's Creative Commons licence and your intended use is not permitted by statutory regulation or exceeds the permitted use, you will need to obtain permission directly from the copyright holder. To view a copy of this licence, visit http://creativecommons.org/licenses/by/4.0/. The Creative Commons Public Domain Dedication waiver (http://creativeco mmons.org/publicdomain/zero/1.0/) applies to the data made available in this article, unless otherwise stated in a credit line to the data. 
Conclusions: Study findings provide a strong foundation for developing and implementing clinical practice guidelines regarding parental tobacco use and child TSE in the PED/UC setting. Future intervention development will address all TDF domains and test the implementation of the intervention in the PED/UC setting.

Keywords: Tobacco smoke exposure, Tobacco counseling, Children, Parents, Pediatric emergency department, Urgent care, Theoretical domains framework, Knowledge, Beliefs about capabilities, Environmental context and resources

\section{Contributions to the literature}

- Literature shows there is suboptimal routine delivery of evidence-based guidelines for tobacco use and tobacco smoke exposure (TSE) screening and counseling in acute healthcare. Pediatric emergency department (PED) and urgent care (UC) patients have disproportionately high rates of TSE.

- The theoretical domains framework (TDF) was used to understand current behavior of tobacco screening and counseling among PED/UC professionals.

- This analysis identifies common barriers and enablers that may influence future intervention development and implementation in the PED/UC setting, and provides researchers with a theoretical rationale for addressing these barriers.

\section{Background}

Tobacco use disorders impose an inordinately large public health burden on emergency departments (EDs) [1]. Parents who bring their children to the pediatric ED (PED) have high cigarette smoking rates ranging from $28 \%$ up to $48 \%[2,3]$ compared with the US general adult population (14\%) [4]. This discrepancy may be due to PEDs commonly caring for those of lower socioeconomic status (e.g., public insurance) [5], which is inversely related to adult smoking [4] and child tobacco smoke exposure (TSE) [6]. PED patients have high rates of TSE, which is defined as exposure to secondhand smoke and thirdhand smoke (i.e., aged secondhand smoke) [7]. Secondhand smoke is inhaled by children from mainstream smoke exhaled by smokers and sidestream smoke from lit tobacco products. Thirdhand smoke is inhaled, orally ingested, and/or dermally transferred from the residual tobacco smoke toxicants that are left behind in the environment after tobacco smoking has been ceased.

The PED is an important venue for child TSE reduction and other modifiable health behavior efforts since this setting is frequently used as both primary and acute care sites by vulnerable patients who do not have access to regular, outpatient primary care [8-11]. Thus, this population needs improved screening and services designed to treat parental tobacco use disorders and reduce child TSE. ED and urgent care (UC) visits constitute a "teachable moment" to promote tobacco-related behavior change $[3,12]$. The emergency setting is generally underutilized for prevention interventions due to perceived lack of time and resources [13]. However, emergency care settings across the US care for a large annual volume of patients [14] and may be ideal venues for preventive care given the long patient wait times and the feasibility of implementing interventions without disrupting clinical flow [3, 15]. Although evidence-based interventions have been effective in the outpatient pediatric setting [16], more research is needed on the barriers to and enablers of effective TSE interventions in the unique PED/ UC setting.

The US Preventive Services Task Force [17] strongly recommends that healthcare professionals screen all patients for tobacco use and provide brief behavioral interventions to help adult tobacco users quit smoking. The US Public Health Service's evidence-based Clinical Practice Guideline, Treating Tobacco Use and Dependence [17], describes five major steps (i.e., the "5A's") to provide brief intervention. These steps are to (1) "ask" about tobacco, (2) "advise" users to quit, (3) "assess" willingness to make a quit attempt, (4) "assist" willing users to make a quit attempt, and (5) "arrange" to help prevent relapse via follow-up. The " 5 A's" framework is the gold standard for brief tobacco screening and intervention delivery in healthcare settings [18]. National guidelines promote the use of the evidence-based " 5 A's" to assist healthcare professionals in the assessment and delivery of treatment for tobacco use and dependence in the general healthcare [17, 19] and ED [1] settings.

PED professionals' screening for parental tobacco use and child TSE and counseling families can reduce TSErelated illness. The US Surgeon General's [18] recent report on smoking cessation indicates that there is sufficient evidence to conclude that the development and dissemination of evidence-based clinical practice guidelines including the " 5 A's" can increase screening for tobacco use and delivery of interventions for smoking cessation in clinical settings. Two meta-analyses of ED-initiated randomized controlled trials (RCTs) concluded that tobacco control efforts promote tobacco abstinence for 
up to one year [20,21]. In addition, parents are satisfied with receipt of the "5 A's" from PED/UC professionals during their children's visits [15]. However, research indicates that PED/UC professionals do not regularly screen for or systematically follow evidence-based guidelines to address parental tobacco use and child TSE [3, 22-27]. There is a need to understand why there is suboptimal delivery of evidence-based guidelines by PED professionals in order to develop strategies for implementing and sustaining consistent adherence to these guidelines.

The theoretical domains framework (TDF) was designed by an expert consensus for implementation research that combines multiple behavior change theories to guide the study, development, and implementation of evidence-based guidelines [28, 29]. The TDF provides an empirical method for assessment of implementation problems and informs implementation of evidence-based practices (e.g., the "5 A's") in clinical settings [28]. The TDF has been used in quantitative tobacco research to assess barriers to and enablers of implementing tobacco prevention and cessation counseling guidelines [30]. A qualitative approach is most frequently used when applying the TDF to identify key behaviors important for implementation of a specific intervention and for intervention development [31]. Therefore, the TDF has also been applied to qualitative tobacco research to gain a better understanding of clinical behaviors related to providing smoking cessation support [32, 33]. This framework was used in the present qualitative study to identify aspects of healthcare professionals' behavior as the first step in adapting and implementing an evidence-based " 5 A's" intervention in the PED/UC setting.

The present study aimed to identify current screening and counseling behaviors of PED/UC nurses, physicians, and healthcare administrators related to parental tobacco use and child TSE and determine barriers and enablers that influence current behavior of delivering evidence-based tobacco counseling. Evidence-based guidelines suggest a systematic approach to developing and implementing TSE interventions [18], and most "5 A's" interventions are delivered using a team-based approach, which involves all members of the healthcare team. Therefore, all three professional groups (nurses, physicians, and administrators) were assessed to ensure all potential team members were represented based on their varying professional roles in the PED/UC setting.

\section{Methods}

\section{Study design and setting}

The study used semi-structured, focused qualitative interviews with $\mathrm{PED} / \mathrm{UC}$ professionals who work at one large, Midwestern tertiary care children's hospital. There are two PEDs and five UCs associated with the hospital that have a collective annual volume of over 150,000 patients, making it one of the busiest in the US. All confidential interviews were conducted and recorded virtually using a secure, research compliant, Internet-based conferencing tool provided by the principal investigator's institution. This study used the Standards for Reporting Qualitative Research (SRQR) items to follow reporting guidelines for qualitative research. Ethical approval for this study was obtained from the University of Cincinnati (institutional review board [IRB] number: 2020-0207) and Cincinnati Children's Hospital Medical Center (IRB number: 2020-0248).

\section{Participants}

Participants were 29 clinical staff with direct patient contact who worked in the PED/UC at the children's hospital. A stratified purposive sample was recruited to ensure views of all professional groups were represented in this study [34]. Participants were limited to the first 30 interested and eligible clinical staff. This included 16 nurses (registered nurses and nurse practitioners), 10 physicians (medical doctors and doctors of osteopathic medicine), and four healthcare administrators (clinical managers and directors). One nurse withdrew, and therefore, a total of 15 nurses were interviewed. A recruitment email was sent to a total of 297 nurses and 76 physicians by the principal investigator via three hospital email listservs to personally invite PED/UC professionals from all areas of clinical practice to participate in the study. Professionals who were interested in participating were instructed to email the principal investigator for more information. The investigator emailed interested and eligible participants who responded with a research information sheet that outlined study details and potential scheduling times for the one-hour virtual interview. Following standard focused interview recommendations [34], PED/UC professionals who consented to participate were individually interviewed until "saturation" (i.e., where no new information emerged) was reached among all professional groups.

\section{Procedure}

All interviews were conducted virtually due to COVID19 restrictions. The principal investigator attended all 29 interviews, introduced the interview study purpose, asked eligible participants if they had any questions about the research information sheet they received via email before participation, and reminded them that they could stop participation at any time. All participants provided verbal consent to participate and to be recorded. Participants received $\$ 50$ compensation for their time and effort 
in the form of a reloadable debit card that was mailed to their homes.

From April 28, 2020 to May 5, 2020, the principal investigator conducted 11 interviews alone, and 18 interviews with another trained study team member (KAF). While the study team member led the 18 interviews, the principal investigator was able to take notes, answer study questions, and ask clarifying questions. Upon interview completion, the principal investigator ordered mechanical transcriptions of the virtual recordings, which were about $70-80 \%$ accurate. Then the study team member used the mechanical transcriptions as a starting point to transcribe each interview verbatim, and finally, removed any potentially identifiable information.

\section{Interview topic guide}

A semi-structured interview guide was developed by the research team, which had expertise in qualitative methods, behavior change, clinical and translational research, emergency medicine, and implementation science. The team consisted of two professors with doctoral degrees in either health education or clinical psychology, two practicing ED and PED/UC medical doctors, and one doctoral-level research assistant. The guide was informed by the TDF, which has 14 theoretical domains derived from 33 validated theories $[28,29]$. The overarching aim of the TDF is to identify elements essential for implementation outcomes $[28,29]$, and is highly correlated with the development and implementation of quality, clinical interventions [35]. The interview guide was piloted during the first two interviews and revised by the principal investigator. Table 1 presents the TDF domains defined by Cane et al. [28], and corresponding interview questions.

\section{Data analysis}

Directed content analysis of qualitative data was guided by the TDF, and data were categorized into the individual TDF domains [31]. The principal investigator (ALM) and a trained study team member (KAF) who co-conducted the interviews started with five transcripts that were randomly selected. The two researchers independently read each transcript, open coded the transcript text, and generated sub-themes that were allocated to the $14 \mathrm{TDF}$ domains. If $\geq 2$ TDF domains were relevant while coding, then they were initially cross-indexed to both domains. After completion of the first five transcripts, the researchers met to discuss their coding and resolve any disagreements and reached consensus on which domain should be selected to best reflect any cross-indexed text, based on the best match to the TDF definition for each domain (see Table 1). If consensus could not be reached, a third study team member (JSG) was available to resolve the conflict. An audit trail was used to define codes and document coding decisions including each TDF domain, sub-theme, and related quotes. It was noted whether sub-themes arose from participants overall, and by professional group. The remaining 24 interviews were independently coded in a random fashion by the same two investigators using the coding guideline. Once the coding process was complete, all interview transcripts were reviewed a second time to enhance analytical rigor and ensure important sub-themes and quotes were not originally overlooked or misapplied.

\section{Results}

Participant characteristics overall, and by professional group, are summarized in Table 2. On average, participants worked 35 hours per week and cared for 51 patients per week. Participants had worked an average of eight years in their current position, and over 14 years at the hospital in any position. Only one participant had received training on tobacco counseling in the past year.

Tables 3, 4, and 5 present TDF domains, sub-themes, and exemplar quotes that emerged regarding factors that influence clinical behaviors and providing the " 5 A's" of tobacco counseling during PED/UC visits. The optimism and goals domains had the fewest sub-themes with only one per each domain, followed by the reinforcement and emotion domains with two sub-themes. The domains with three sub-themes were skills; social/professional role and identity; beliefs about consequences; intentions; memory, attention, and decision processes; social influences; and behavioral regulation. The knowledge, beliefs about capabilities, and environmental context and resources domains each had the most (four) sub-themes.

\section{Knowledge domain}

Specific to the knowledge domain, healthcare professionals observed the barrier that they had a lack of knowledge in both (1) tobacco counseling and (2) how to implement counseling into the PED/UC visits (see Table 3). They also observed that they need more information on (3) smoking cessation resources and referral options and (4) thirdhand smoke education to provide to families. Specific to thirdhand smoke, all three professional groups noted that when they perform the "advise" step, they explain the importance of taking proper precautions after smoking (e.g., changing clothes, washing hands) to protect children from thirdhand smoke found on smokers' clothes and skin. PED/UC professionals also noted that parents, especially those who try to protect their children from secondhand smoke by smoking outside of the home and not around the child, are typically surprised by this information. Professional group differences were found in the knowledge domain sub-theme regarding availability of information on thirdhand smoke. Nurses and 


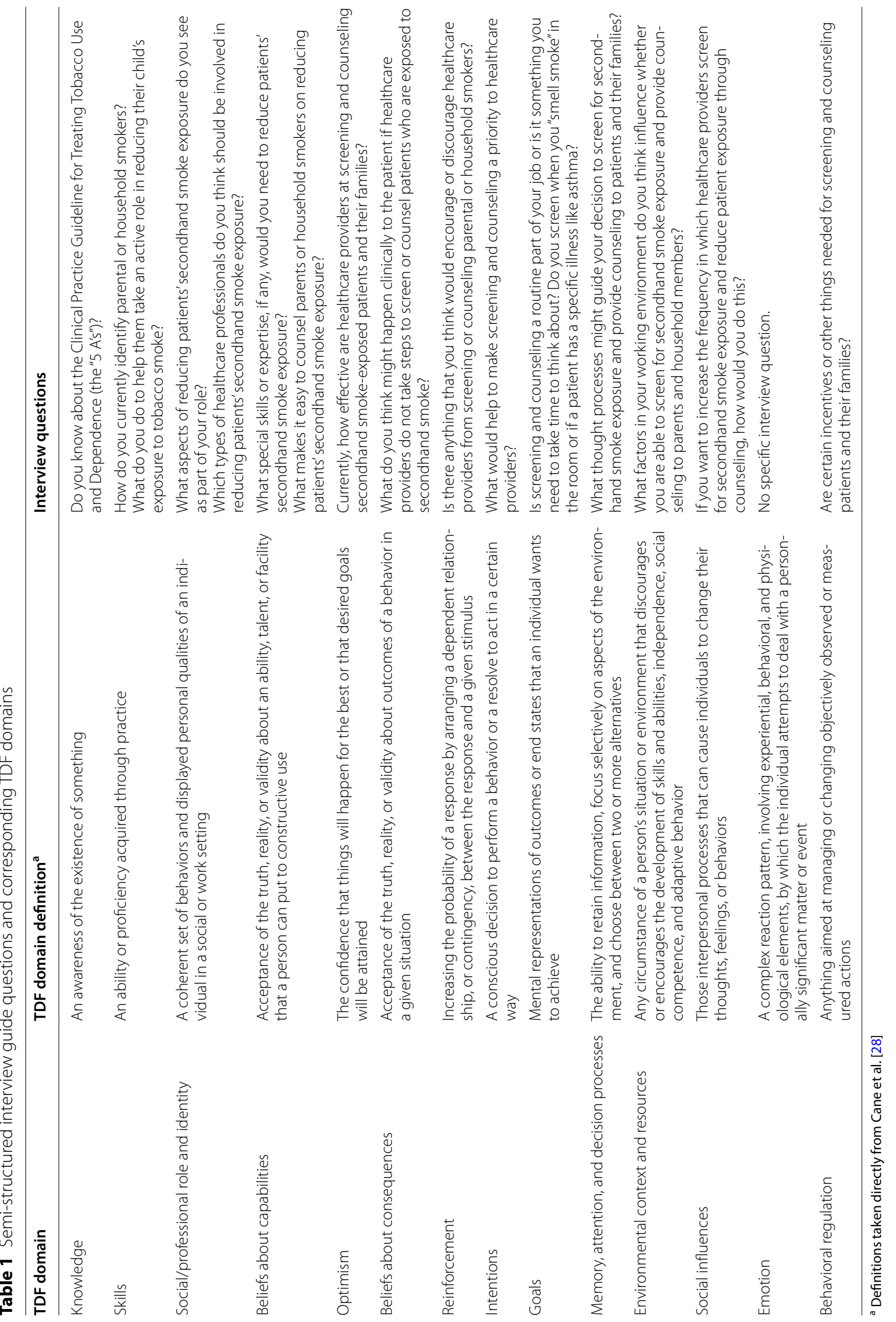


Table 2 PED/UC professional characteristics overall and by professional group

\begin{tabular}{|c|c|c|c|c|}
\hline Characteristic & $\begin{array}{l}\text { Overall }(N=29) \\
n^{\mathrm{a}}\end{array}$ & $\begin{array}{l}\text { Nurse }(n=15) \\
n^{\text {a }}\end{array}$ & $\begin{array}{l}\text { Physician }(n=10) \\
n^{\text {a }}\end{array}$ & $\begin{array}{l}\text { Administrator }(n=4) \\
n^{\mathrm{a}}\end{array}$ \\
\hline Age, $M$ (SD) & $42.4(10.1)$ & $38.5(10.0)$ & $44.0(6.6)$ & $52.8(11.3)$ \\
\hline \multicolumn{5}{|l|}{ Sex } \\
\hline Male & 5 & 0 & 3 & 2 \\
\hline Female & 24 & 15 & 7 & 2 \\
\hline \multicolumn{5}{|l|}{ Race/ethnicity } \\
\hline Non-Hispanic White & 27 & 15 & 8 & 4 \\
\hline Non-Hispanic Other/Unknown & 2 & 0 & 2 & 0 \\
\hline \multicolumn{5}{|l|}{ Education level } \\
\hline College graduate/some post-college & 9 & 9 & 0 & 0 \\
\hline Master's degree & 8 & 6 & 0 & 2 \\
\hline MD/DO & 12 & 0 & 10 & 2 \\
\hline \multicolumn{5}{|l|}{ Tobacco use status } \\
\hline Never tobacco user & 25 & 13 & 9 & 3 \\
\hline Former tobacco user & 3 & 2 & 0 & 1 \\
\hline Unknown (did not wish to answer) & 1 & 0 & 1 & 0 \\
\hline \multicolumn{5}{|l|}{ E-cigarette use status } \\
\hline Never e-cigarette user & 29 & 15 & 10 & 4 \\
\hline No. of work hours/week, $M$ (SD) & $35.0(10.9)$ & $29.7(7.3)$ & $40.3(13.5)$ & $41.3(5.5)$ \\
\hline No. of patients cared for/week, $M$ (SD) & $51.0(34.0)$ & $55.1(38.2)$ & $57.0(28.7)$ & $20.3(7.8)$ \\
\hline No. of years in current position, $M$ (SD) & $8.1(8.5)$ & $8.6(9.6)$ & $9.2(8.0)$ & $3.3(2.8)$ \\
\hline No. of years at the hospital in any position, $M(\mathrm{SD})$ & $14.1(8.4)$ & $13.1(8.5)$ & $13.7(6.9)$ & $19.0(11.7)$ \\
\hline \multicolumn{5}{|l|}{ Past year training on tobacco counseling } \\
\hline No & 26 & 14 & 8 & 4 \\
\hline Yes & 1 & 0 & 1 & 0 \\
\hline Don't know & 2 & 1 & 1 & 0 \\
\hline
\end{tabular}

${ }^{a} n$ unless noted otherwise

physicians identified the barrier of lacking educational materials to provide to parents about thirdhand smoke to reinforce the information they presented while administrators did not.

\section{Beliefs about capabilities and environmental context and resources domains}

The beliefs about capabilities domain also had four specific sub-themes (see Table 3). Overall, PED/UC professionals reported the (1) barrier that they were uncomfortable with discussing tobacco counseling with parents, (2) enabler that it is easier to have discussions about parental tobacco use and child TSE when the parents are open and receptive to counseling, (3) enabler that it is easier to discuss tobacco use and TSE when the child has a TSE-related chief complaint (e.g., cough) or illness (e.g., asthma), and (4) enabler that they would be more confident and likely to discuss parental tobacco use if there were available guidelines, smoking cessation resources, and referral options to provide to the parents during the visit.
The environmental context and resources domain revealed similar but distinct themes. PED/UC professionals suggested they need the following enablers: (1) tobacco cessation resources and referral information to give to parents, (2) training and aids to facilitate discussion of the sensitive topic of tobacco use with parents, and (3) the child's reason of visit to be potentially related to TSE to provide an opportunity and context to offer tobacco counseling to parents during the visit (see Table 3). Additionally, (4) the barrier of lack of time for prevention in the PED/UC environment was noted as the biggest obstacle to providing tobacco counseling.

\section{Skills, social/professional role and identity, and optimism domains}

The next set of domains, presented in Table 4, that emerged during interviews were skills, social/professional role and identity, and optimism. Concerning the skills domain, (1) all PED/UC professional groups reported the barriers of difficulty initiating a discussion about tobacco use with parents, and after identifying parental smokers, 


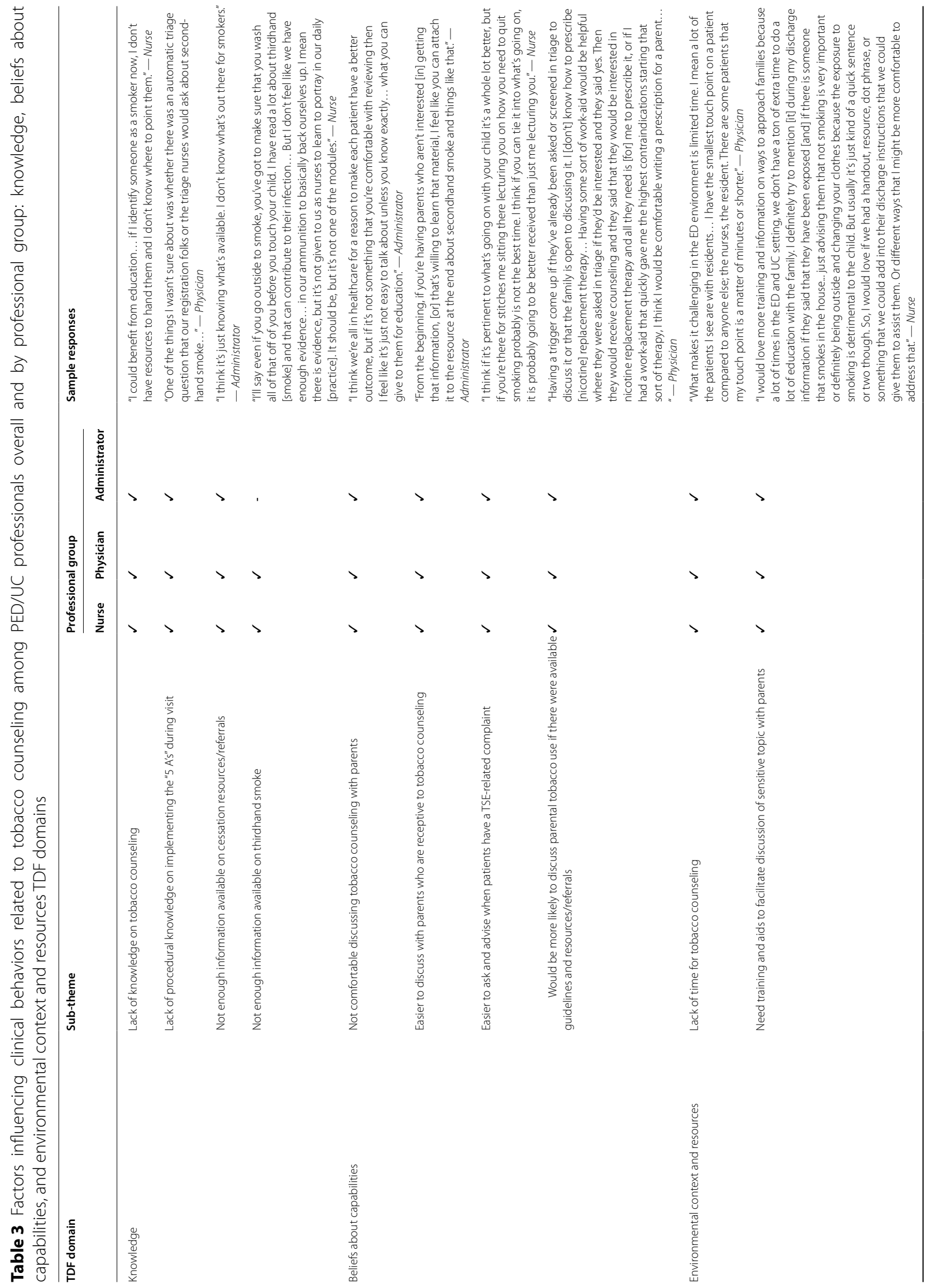




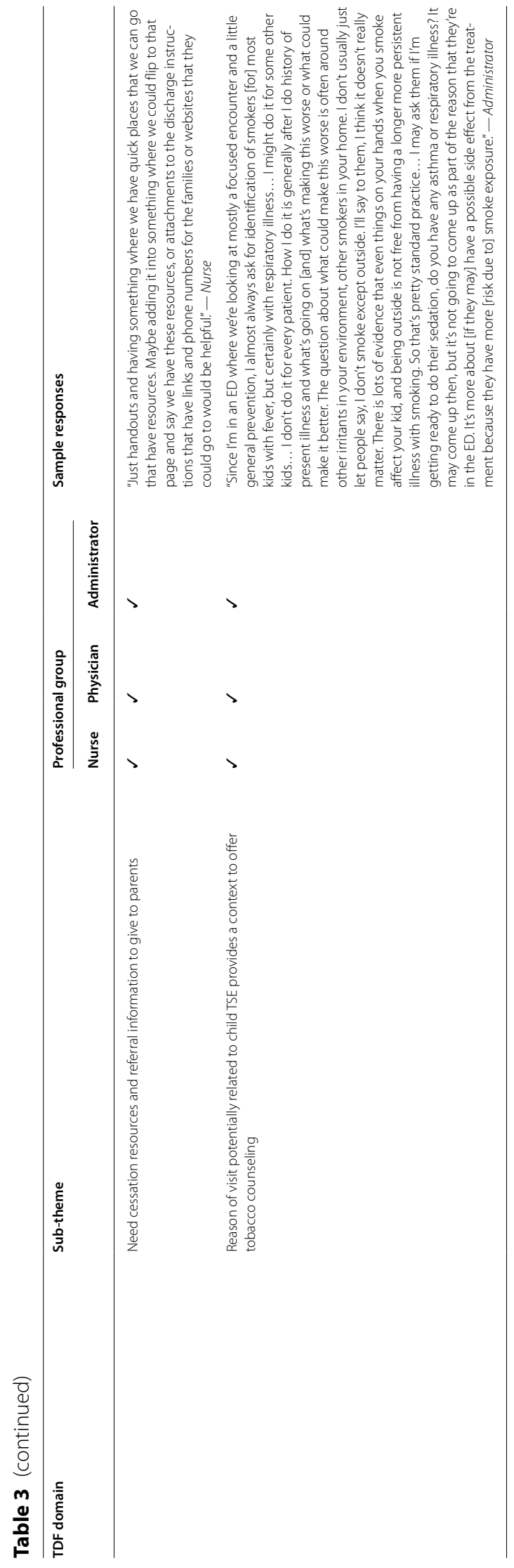




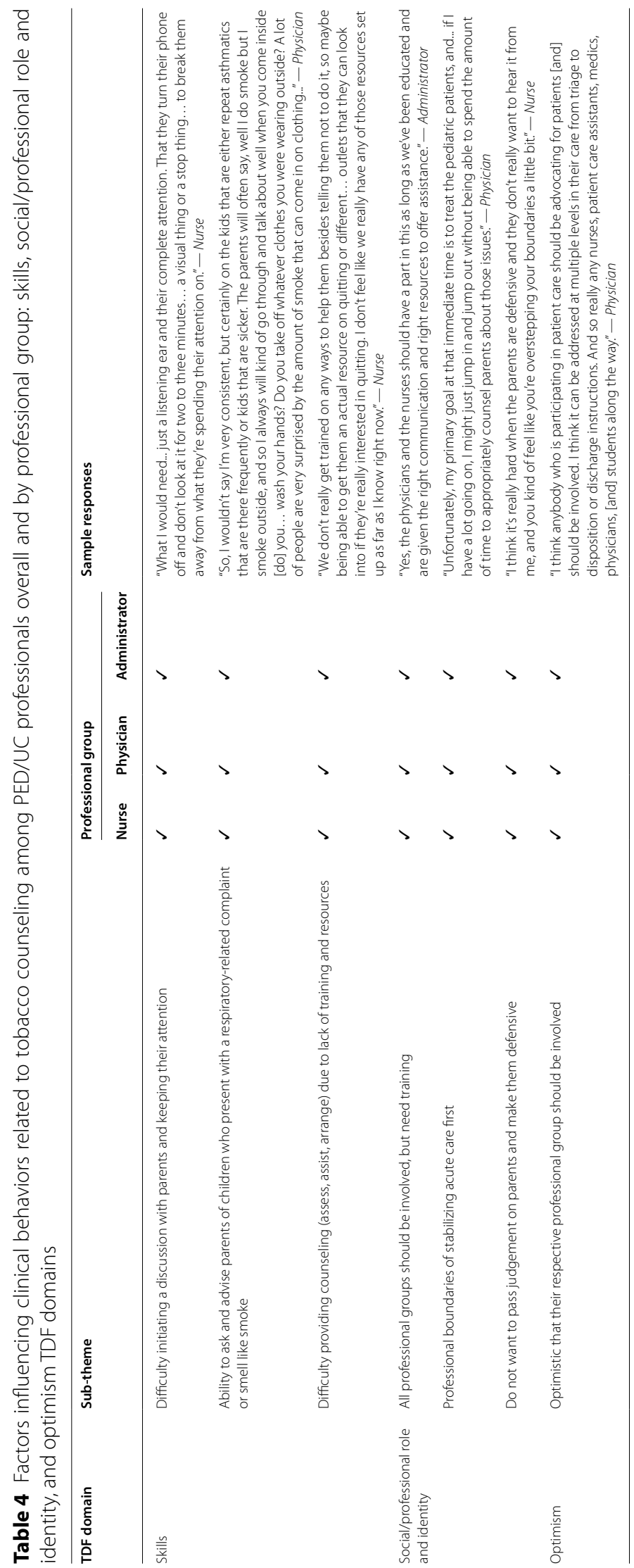




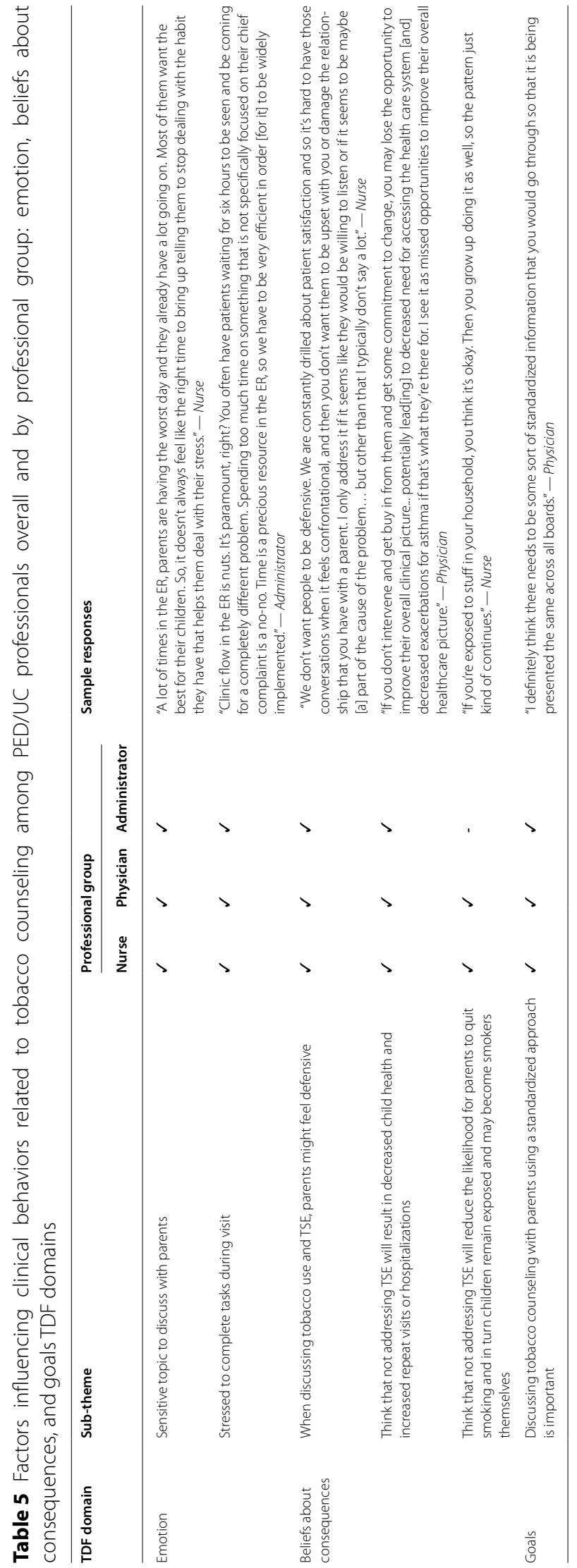


difficulty keeping their attention. Healthcare professionals also observed the enabler that they were (2) more skilled in asking about tobacco use and advising parental smokers of children who presented with a TSE-related complaint or smelled like smoke, but observed the barrier that they were (3) less skilled in counseling and assessing parents' willingness to quit smoking, and assisting/arranging them with cessation support.

For the social/professional role and identity domain, (1) PED/UC professionals identified the barrier that discussing tobacco use behavior may come across as passing judgment on parents, thus, making parents defensive. Although all professional groups identified that (2) training all professional groups would enable implementation, (3) they also identified professional boundaries as a barrier since their primary role is to provide acute care to PED/UC patients. The optimism domain belief shared by all professional groups was that their respective group should be involved in tobacco counseling efforts.

\section{Emotion, beliefs about consequences, and goals domains}

While only two sub-themes emerged for the emotion domain, it is important to note that most PED/UC professionals, across groups, shared two barriers to implementation: (1) tobacco use is a sensitive topic to discuss with parents and (2) they are already stressed to complete tasks related to stabilizing acute care of their patients during visits (Table 5). Many professionals used the words "defensive," "offended," "attacked," and "threatening" while describing how they perceived parents' emotions while discussing their tobacco use behavior during past PED/UC visits. Most PED/UC professionals in all three groups shared a belief about consequences that a barrier to implementation is that parents may be defensive. To avoid making parents defensive and non-receptive, $\mathrm{PED} / \mathrm{UC}$ professionals in all three groups described using a universal, standardized approach as an enabler of their goals to discuss tobacco counseling with parents (see Table 5). Another beliefs about consequences sub-theme discussed by all groups was that not addressing parental tobacco use and child TSE will decrease the overall health of PED/UC patients. Only nurses and physicians discussed the perceived consequence that not addressing tobacco use and TSE increases the potential for patients to become smokers in the future.

\section{Intentions; memory, attention, and decision processes; social influences; behavioral regulation; and reinforcement domains}

The remaining domains that emerged during interviews presented in Table 6 were intentions; memory, attention, and decision processes; social influences; and behavioral regulation. Specifically, PED/UC professionals stated that their intentions to screen for parental tobacco use and child TSE and advise parental smokers to quit smoking are higher when (1) the patient presents with a TSE-related complaint and illness and (2) the patient's room smells like smoke. However, (3) their intentions to screen and counsel are lower when they have competing time demands of stabilizing acute care and fast patient turnover time. Further, all PED/UC professional groups reported the memory, attention, and decision processes domain sub-theme that (1) the topic of tobacco counseling was not thought of unless their patient presents with a TSE-related complaint and illness. Only nurses and physicians identified two of the memory, attention, and decision processes domain sub-themes as barriers: (2) the topic of tobacco counseling was not thought of unless the patients' room smells like smoke and (3) there are no reminders to provide tobacco counseling during visits.

All PED/UC professional groups discussed social influences and shared their reluctance to ask about parental tobacco use. Specifically, PED/UC professionals reported the following barriers that they (1) believed parental smokers lack interest in receiving tobacco counseling, (2) do not know what motivates parents to smoke tobacco, and (3) find it difficult to build rapport with parents during their child's visit. Overall, the professional groups perceived the following would provide them with behavioral regulation: (1) requiring screening for parental tobacco use, (2) receiving tobacco use counseling training and discussion aids, and (3) having electronic information to give to parents. The three PED/UC professional groups also discussed that (1) implementing tobacco and TSE screening questions into the routine clinical flow and (2) receiving feedback on the PED/UC patients' clinical benefit of providing tobacco use counseling to their parents would reinforce the importance of providing counseling to parents who are not their patients.

\section{Discussion}

In preparation for future intervention development, the present study used the TDF and identified PED/UC professionals' current clinical behaviors related to parental tobacco use and child TSE counseling, influences on this behavior, and perceived roles and responsibilities. All TDF domains emerged during the interviews with nurses, physicians, and administrators, with some variation among professional groups where nurses and physicians shared sub-themes, but administrators did not. Key barriers and enablers were identified across professional groups as outlined below.

The major barriers reported by nurses, physicians, and administrators were lack of knowledge, resources, and training on evidence-based tobacco counseling. These barriers emerged in the knowledge; skills; social/ 


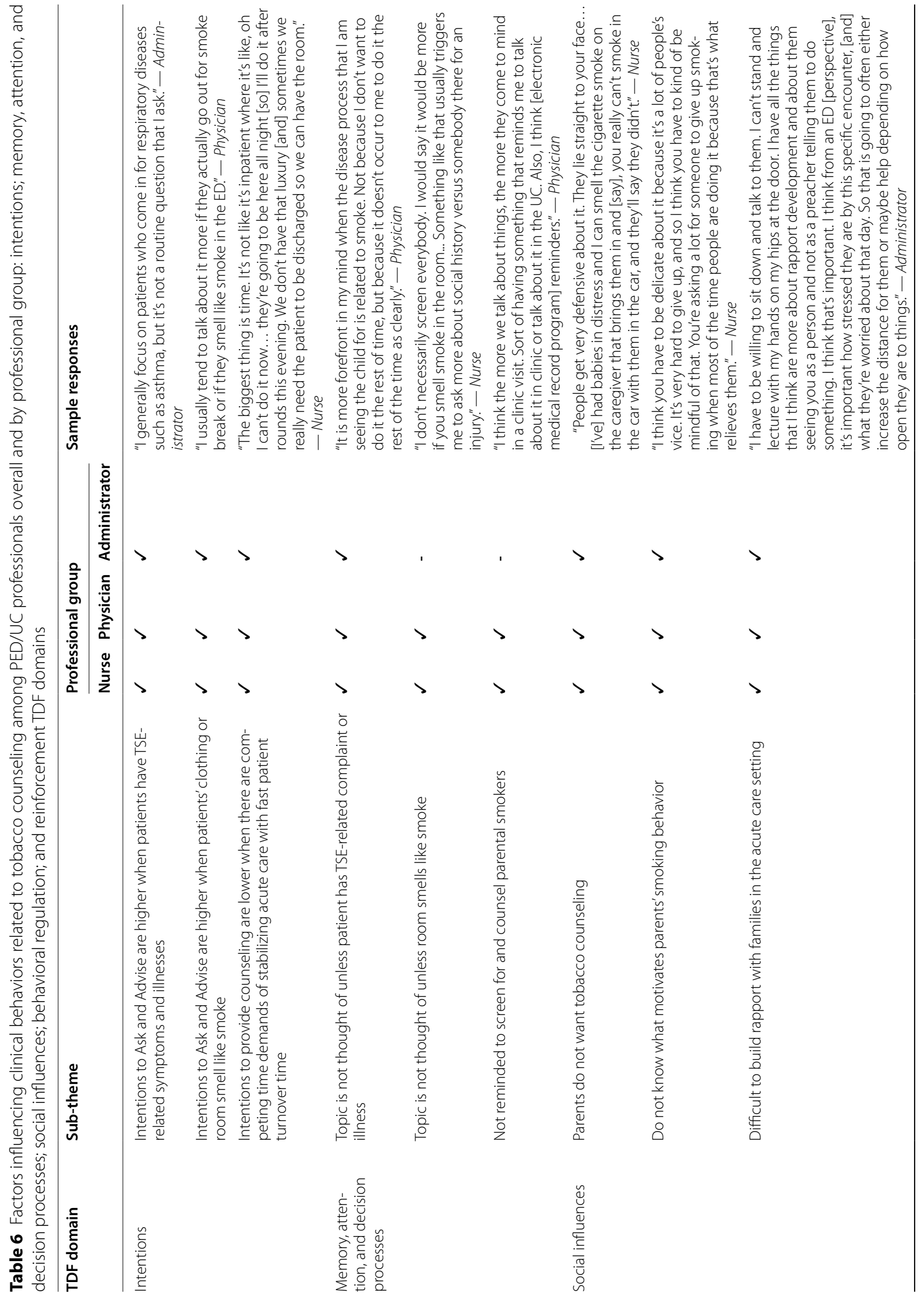




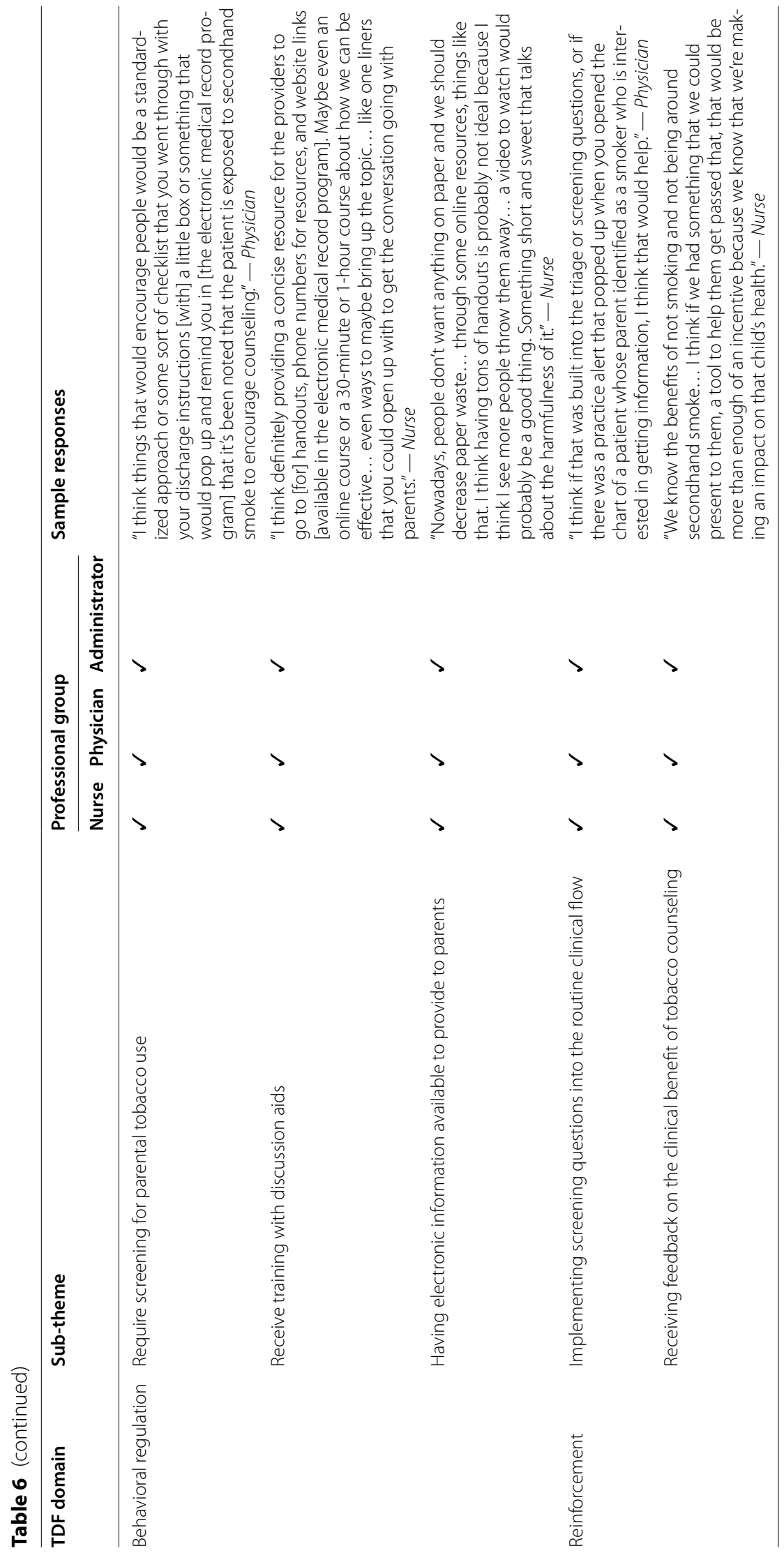


professional role and identity; beliefs about capabilities; reinforcement; memory, attention, and decision processes; environmental context and resources; social influences; and behavioral regulation domains. Our findings confirm past PED/UC research that reported limited general knowledge about tobacco counseling and available resources [36]. Overall, PED/UC professionals' adherence to the Clinical Practice Guideline of Treating Tobacco Use and Dependence [17] were mixed, and those who performed tobacco counseling usually only performed the "ask" and "advise" steps. This aligns with prior research that indicates ED professionals often "ask" and "advise," but infrequently proceed to the next three steps [22, 3739]. Further, PED/UC professionals noted that they are not skilled beyond asking and advising due to the barriers of lack of training and resources. This aligns with the US Surgeon General's Report on Smoking Cessation [18] that screening for tobacco use is completed during twoin-three clinical visits compared to providing counseling or education to adult tobacco users, which is done about every one-in-five visits.

Encouragingly, all three PED/UC professional groups revealed they would feel more capable and have higher self-efficacy to perform tobacco counseling, especially the "assess" and "assist/arrange" steps, if there were available guidelines, resources, and referral options for parents and families. There are several available online resources and training tools for healthcare providers (e.g., Tobacco Treatment Specialist certification training [40]) and administrators (e.g., Best Practices for Comprehensive Tobacco Control Programs [41]) to facilitate treatment of tobacco use in the clinical settings [42]. One recommended component of PED/UC professional training is motivational interviewing [17], a collaborative, person-centered counseling technique that can be used to assist smokers in exploring and resolving ambivalence about quitting smoking [43]. A systematic review and meta-analysis of RCTs that evaluated the efficacy of ED-initiated tobacco control found that motivational interviewing and booster phone calls increased tobacco abstinence at 12-month follow-up [21]. Thus, training in motivational interviewing and evidencebased resources and referrals may help to alleviate PED/ UC professionals' concerns about engaging parents in meaningful conversations about their tobacco use. All three professional groups discussed the preference for electronic information and resources on quitting (e.g., cell phone texting), rather than paper-based information and resources (e.g., written self-help packet) to provide to parents and families.

Our study also revealed a knowledge domain sub-theme that materials and information on thirdhand smoke exposure are not available to give to patients' families. A priority for programmatic TSE research is to distinguish thirdhand smoke exposure-specific health risks from secondhand smoke exposure health risks [7]. Current research aims to address the existing knowledge gap on the clinical effects of exclusive thirdhand smoke exposure and pollution among PED/UC patients [44]. Emerging evidence-based research and resources on thirdhand smoke exposure could be tailored to the PED/UC setting. These include freely available educational materials at thirdhandsmoke.org (e.g., webinars [45]). Research on the Clinical Effort Against Secondhand Smoke Exposure (CEASE) intervention to address parental tobacco use during primary care visits shows that sensitizing parents to risks of thirdhand smoke exposure during their children's primary care visits may positively affect their child's health [46]. Additionally, parents who believe thirdhand smoke exposure harms their children's health were more likely to have strict and voluntary home and/ or car smoking bans and make at least one quit attempt 12-months later. However, much less is known about offering this type of intervention in the PED/UC setting. The nurse and physician groups in this study indicated that although they verbally share potential health harms of thirdhand smoke exposure with parents (e.g., research showing that $\mathrm{PED} / \mathrm{UC}$ patients have nicotine on their hands even when no one is smoking around them $[47,48])$, they do not have enough evidence-based information on thirdhand smoke to provide to families. Therefore, nurses and physicians expressed a need for materials to provide to families to reinforce what they discussed with them about thirdhand smoke exposure. Further research is needed to establish and test the use of evidence-based materials and messaging on the clinical risks of thirdhand smoke exposure in the PED/UC setting.

Another barrier perceived by all three professional groups is the lack of a standardized protocol for implementing tobacco counseling during the PED/UC visit, which emerged in the reinforcement; intentions; goals; memory, attention, and decision processes; and behavioral regulation TDF domains. PED/UC professionals in all groups mentioned that requiring screening for parental tobacco use and child TSE would objectively change their behavior to initiate tobacco counseling. A barrier cited by all PED/UC professional groups is that they were not reminded to screen and counsel during the visit. To overcome this barrier, the three PED/UC professional groups suggested the need to implement routine parental tobacco use and child TSE screening questions into the PED/UC flow. Prior qualitative work with ED nurses and physicians suggested the need for acute healthcare systems to implement standardized tobacco counseling practice policies, including incorporating tobacco 
control interventions into the clinical flow and clarifying professionals' roles and responsibilities in offering these interventions [49]. All professional groups in this study noted that their immediate role is to stabilize acutely ill patients, and this is a barrier to conducting tobacco screening and counseling during every visit. However, all professional groups were enthusiastic about being involved in tobacco counseling and perceived that their respective groups should be involved and trained in offering tobacco counseling.

Another major barrier cited by PED/UC professionals was that they did not want to seem judgmental towards parental smokers as this may make parents defensive. This barrier emerged during the skills, social/professional role and identity, beliefs about consequences, intentions, goals, environmental context and resources, social influences, and emotion domains. Thus, having a standardized system in place could assist in determining when to and who should routinely screen for child TSE and/ or offer tobacco counseling to tobacco users. Similar to other research [49], smokers' resistance was frequently cited as a perceived barrier to providing tobacco counseling. Another shared perception of all three professional groups was difficulty initiating a discussion about tobacco use with parents and keeping their attention. For example, this study had reports of parents being on their cell phones during their child's entire visit. Thus, PED/ UC professionals perceived their attention span and body language as non-verbal cues of lack of interest in receiving tobacco counseling. This parallels qualitative research in the adult ED setting that reported assessing non-verbal cues (e.g., rolling eyes when topic is brought up) to gauge patients' receptiveness to tobacco counseling [49]. The current study's results underscore the need for a standardized approach to delivering tobacco counseling interventions in the $\mathrm{PED} / \mathrm{UC}$ setting. This approach could include asking all parents about their child's TSE status with the triage questions, determining their receptivity and motivation, and tailoring interventions based on their response.

$\mathrm{PED} / \mathrm{UC}$ professionals identified that leveraging a potential TSE-related complaint (e.g., cough) as a context to provide tobacco counseling to parents would further enable their screening and counseling behaviors. PED/ UC professionals frequently stated that they have an easier time asking and advising receptive parents about their child's TSE, especially those who present with a TSE-related complaint (e.g., cough, asthma), compared with resistant or unresponsive parents. All three professional groups felt skilled in and had increased intentions to ask and advise parents of patients who presented with a TSE-related complaint and/or if the room or patient smelled like smoke. Acute healthcare studies have also shown that providers typically ask about tobacco use when patients present for health conditions (e.g., respiratory illnesses) related to smoking [39], and TSE [36]. The current study's findings expand on these studies by also noting the smell of thirdhand smoke residue deposited on children and their parents' clothes and skin, as an important enabler of their intentions to provide tobacco counseling. While children presenting with a TSE-related complaint or illness and the room smelling like smoke are reminders to screen for child TSE, universal screening for child TSE is recommended during each pediatric visit [50]. One potential strategy is the use of clinical decision support system (CDSS) tools that can be seamlessly incorporated into the PED/UC flow and can provide rates of TSE screening and tobacco use counseling via electronic medical record queries [51]. A CDSS could facilitate universal screening and counseling based on the "5 A's" steps, which may mitigate the barrier of parents being defensive or feeling "singled out." Therefore, future interventions should test ways to screen for child TSE during every visit, and assess CDSS use rates.

Two additional barriers to implementing interventions cited by all professional groups were lack of (1) time during the visit and (2) available PED/UC-based resources. These barriers emerged in the beliefs about capabilities; reinforcement; intentions; memory, attention, and decision processes; environmental context and resources; and emotion domains. Intentions to provide counseling were lower when PED/UC professionals had competing acute care-related time demands coupled with a fast patient turnover time. Also, the stress of completing acute carerelated tasks during the visit due to time constraints was also identified. Lack of time and resources have been widely cited among ED/PED-based general preventive intervention research (e.g., vaccinations) [11] and tobacco control research [36, 38, 52, 53].

Healthcare professionals can make a difference in increasing overall tobacco abstinence rates with minimal, low-intensity counseling interventions of less than three minutes [17]. Evidence indicates that ED-based screening, brief intervention, and referral to treatment (SBIRT) programs can be cost-effective and cost-beneficial for substance use disorder management among at-risk patients $[54,55]$. The PED/UC setting has been used to successfully deliver brief cessation counseling to parental smokers using the SBIRT approach; results indicate that these brief counseling sessions resulted in increases in quit attempts and decreases in tobacco use among parents [56]. An RCT conducted at four EDs in Hong Kong found that brief advice of around one minute that included a message about high smoking-related mortality risks, advice to quit, and referring adult patients to quitline services increased biochemically validated quit rates 
up to 12-months later, compared to the control group that received a tobacco cessation leaflet [57]. Another potential strategy to reduce the barrier of lack of time is to briefly introduce tobacco counseling to parents during the visit and assisting/arranging them with an active e-referral to a tobacco quitline [58]. Additionally, using a team-based approach and including other PED/UC staff (e.g., social worker) into tobacco efforts would expand available PED/UC-based resources. For example, prior research indicates that mental health counselors can be effective in providing brief interventions for substance use disorders [59], and a computerized tobacco program promoted treatment initiation [60]. Therefore, a multidisciplinary team-based approach should be considered for delivery of future interventions.

All three professional groups expressed that a consequence of not addressing child TSE during the visit is decreased overall health and repeated $\mathrm{PED} / \mathrm{UC}$ visits or hospitalizations. These concerns are supported by prior $\mathrm{PED} / \mathrm{UC}$ research which found that when compared with unexposed children, tobacco smoke-exposed children are at increased odds of having higher resource and medication utilization during visits and are more likely to be admitted to the hospital [61]. Additionally, exposed PED/ $\mathrm{UC}$ patients are at increased risk of having higher PED costs at their initial visit, followed by greater UC visits and hospitalizations 12-months following their initial visit [62]. Among exposed PED/UC patients only, those with higher cotinine levels had increased risk of having PED visits and hospital admissions over 6-months [63]. PED/UC nurses and physicians also expressed the concern that their patients may initiate smoking in the future, which is also supported by evidence [64]. Therefore, another potential strategy to encourage implementation is to include feedback on the clinical benefit of intervening with families during the PED/UC visit. For example, it may be helpful to provide PED/UC professionals with a summary of the number of children with TSE they identified and parental tobacco cessation rates 6-months following the initial visit. Therefore, providing information on the clinical benefits of intervention (e.g., reductions in the number of tobacco smoke-exposed children who had repeat PED/UC visits or hospitalizations 6-months following their initial visit) should be included in future interventions.

\section{Limitations}

The current study's limitations should be noted. This study was a sample of PED/UC professionals at one large, Midwestern children's hospital where a future intervention will be developed and implemented. Therefore, professionals' views may differ from the general PED/UC professional population's views. Additionally, some PED/ UC professionals were familiar with the study team's tobacco control research, which may have skewed perceptions and their current practices (e.g., sharing the study team's work on thirdhand smoke exposure). Further, our qualitative synthesis and results showed that there may be connections between TDF domains (e.g., knowledge and beliefs about capabilities), but the TDF does not allow for such examination of these links since there are not validated measures to assess associations. However, future research should assess compliance with the "5 A's" as this will elucidate adherence with the recommended TSE screening and counseling practices. Future research should also consider observing PED/UC professionals during the visits.

\section{Conclusions}

This study's findings support the need to develop and implement an intervention to support PED/UC professionals in their tobacco prevention and control practices. The TDF provided rich, valuable qualitative data to understand current clinical behaviors in following the Clinical Practice Guideline of Treating Tobacco Use and Dependence [17] and provided a framework for future intervention development and implementation. Thus, the planned intervention will address the range of barriers through use of the enablers identified during interviews with PED/UC professionals. Sample intervention components include a standardized approach using a CDSS within the electronic medical record delivered during optimal times within a visit, brief counseling that uses motivational interviewing techniques, a teambased approach for intervention delivery, and providing feedback reports to the healthcare team on the benefits of the intervention on child and parental health. Intervention development and implementation plans will address all TDF domains, include tobacco training, and test the most effective methods, resources, intensity, and timing of intervention delivery in the PED/UC setting.

\section{Abbreviations}

ED: Emergency department; PED: Pediatric emergency department; UC: Urgent care; TSE: Tobacco smoke exposure; TDF: Theoretical domains framework; IRB: Institutional review board; RCT: Randomized controlled trial.

\section{Acknowledgements}

The authors are grateful to the Cincinnati Children's Hospital Medical Center's Pediatric Emergency Department leadership who supported the recruitment of healthcare professionals. The authors would like to thank all professionals who participated in this study. 


\section{Authors' contributions}

ALM conceptualized and designed the study, conducted interviews, analyzed and interpreted the data, drafted the manuscript, and approved the final manuscript as submitted. KAF conducted the interviews, analyzed and interpreted the data, drafted the manuscript, and approved the final manuscript as submitted. JSG conceptualized and designed the study, supervised the analysis and interpretation of data, revised the manuscript for important intellectual content, and approved the final manuscript as submitted. MSL conceptualized and designed the study, revised the manuscript for important intellectual content, and approved the final manuscript as submitted. EMMG conceptualized and designed the study, supervised the acquisition and interpretation of data, revised the manuscript for important intellectual content, and approved the final manuscript as submitted.

\section{Funding}

This study was funded by the National Institute on Drug Abuse (NIH Grant Number K01DA044313) and National Institute of Environmental Health Sciences (NIH Grant Numbers R21ES032161, R01ES027815, and R01ES030743).

\section{Availability of data and materials}

The dataset generated and/or analyzed during the current study are not publicly available due to the potential risk of identification of participants, but a limited dataset is available from the corresponding author on reasonable request.

\section{Declarations}

\section{Ethics approval and consent to participate}

The Institutional Review Boards at the University of Cincinnati (\#2020-0207) and Cincinnati Children's Hospital Medical Center (\#2020-0248) approved this study. Consent to participate was obtained from all healthcare professionals who took part in this study.

\section{Consent for publication}

Consent for publication was obtained from all participants who took part in this study.

\section{Competing interests}

The authors declare that they have no competing interests.

\section{Author details}

${ }^{1}$ School of Human Services, University of Cincinnati, P.O. Box 210068, Cincinnati, OH 45221-0068, USA. ${ }^{2}$ Center for Addiction Research, College of Medicine, University of Cincinnati, Cincinnati, $\mathrm{OH}$, USA. ${ }^{3}$ Division of Emergency Medicine, College of Medicine, Cincinnati Children's Hospital Medical Center, University of Cincinnati, 3333 Burnet Avenue, Cincinnati, OH 45229, USA. ${ }^{4}$ Department of Emergency Medicine, College of Medicine, University of Cincinnati, 231 Albert Sabin Way, Cincinnati, OH 45267-0769, USA. ${ }^{5}$ College of Nursing, The University of Arizona, 1305 N Martin Avenue, PO Box 210203, Tucson, AZ 85721-0203, USA.

\section{Received: 20 February 2021 Accepted: 14 December 2021}

Published online: 12 January 2022

\section{References}

1. Bernstein SL, Boudreaux ED, Cydulka RK, Rhodes KV, Lettman NA, Almeida $S$, et al. Tobacco control interventions in the emergency department: a joint statement of emergency medicine organizations. Ann Emerg Med. 2006;48(4):e417-26. https://doi.org/10.1016/j.annemergmed.2006.02.018.

2. Merianos AL, Dixon CA, Mahabee-Gittens EM. Tobacco smoke exposurerelated illnesses among pediatric emergency department patients. J Pediatr Health Care. 2016;31(2):161-6. https://doi.org/10.1016/j.pedhc. 2016.07.001.

3. Mahabee-Gittens EM, Khoury JC, Ho M, Stone L, Gordon JS. A smoking cessation intervention for low-income smokers in the ED. Am J Emerg Med. 2015;33(8):1056-61. https://doi.org/10.1016/j.ajem.2015.04.058.
4. Cornelius ME, Wang TW, Jamal A, Loretan CG, Neff LJ. Tobacco product use among adults - United States, 2019. MMWR Morb Mortal Wkly Rep. 2020;69(46):1736-42. https://doi.org/10.15585/mmwr.mm6946a4.

5. Deakyne Davies SJ, Grundmeier RW, Campos DA, Hayes KL, Bell J, Alessandrini EA, et al. The Pediatric Emergency Care Applied Research Network registry: a multicenter electronic health record registry of pediatric emergency care. Appl Clin Inform. 2018;9(2):366-76. https://doi.org/10. 1055/s-0038-1651496.

6. Brody DJ, Lu Z, Tsai J. Secondhand smoke exposure among nonsmoking youth: United States, 2013-2016. In: NCHS Data Brief, no 348. Hyattsville: National Center for Health Statistics; 2019.

7. Jacob P, Benowitz NL, Destaillats H, Gundel L, Hang B, Martins-Green M, et al. Thirdhand smoke: new evidence, challenges, and future directions. Chem Res Toxicol. 2017;30(1):270-94. https://doi.org/10.1021/acs.chemr estox.6b00343.

8. Whitfill T, Auerbach M, Scherzer DJ, Shi J, Xiang H, Stanley RM. Emergency care for children in the United States: epidemiology and trends over time J Emerg Med. 2018;55(3):423-34. https://doi.org/10.1016/j.jemermed. 2018.04.019.

9. Chamberlain JM, Krug S, Shaw KN. Emergency care for children in the United States. Health Aff. 2013;32(12):2109-15. https://doi.org/10.1377/ hlthaff.2013.0871.

10. Bernstein SL. The clinical impact of health behaviors on emergency department visits. Acad Emerg Med. 2009;16(11):1054-9. https://doi.org/ 10.1111/j.1553-2712.2009.00564.x.

11. Rhodes KV, Gordon JA, Lowe RA. The Society for Academic Emergency Medicine Public Health and Education Task Force Preventive Services Work Group. Preventive care in the emergency department, part I: clinical preventive services - are they relevant to emergency medicine? Acad Emerg Med. 2000;7(9):1036-41. https://doi.org/10.1111/j.1553-2712.2000. tb02097.x.

12. Hawk K, D'Onofrio G. Emergency department screening and interventions for substance use disorders. Addict Sci Clin Pract. 2018;13(1):18-6. https://doi.org/10.1186/s13722-018-0117-1.

13. Bernstein SL, Haukoos JS. Public health, prevention, and emergency medicine: a critical juxtaposition. Acad Emerg Med. 2008;15(2):190-3. https://doi.org/10.1111/j.1553-2712.2008.00055.x.

14. Cairns C, Kang K, Santo L. National Hospital Ambulatory Medical Care Survey: emergency department summary tables; 2018. Available from: https://www.cdc.gov/nchs/data/nhamcs/web_tables/2018_ed_web_ tables-508.pdf

15. Mahabee-Gittens EM, Merianos AL, Dexheimer JW, Meyers GT, Stone L, Tabangin $\mathrm{M}$, et al. Utilization of a clinical decision support tool to reduce child tobacco smoke exposure in the urgent care setting. Pediatr Emerg Care. 2020;36(11):527-31. https://doi.org/10.1097/PEC.0000000000 001646.

16. Massachusetts General Hospital: CEASE. 2016. www.ceasetobacco.org (2016). Accessed February 7, 2021.

17. The Clinical Practice Guideline Treating Tobacco Use and Dependence 2008 Update Panel, Liaisons, and Staff. A clinical practice guideline for treating tobacco use and dependence: 2008 update. Am J Prev Med. 2008;35(2):158-76. https://doi.org/10.1016/j.amepre.2008.04.009.

18. U.S. Department of Health and Human Services. Smoking cessation: report of the Surgeon General. Atlanta: U.S. Department of Health and Human Services, Centers for Disease Control and Prevention, National Center for Chronic Disease Prevention and Health Promotion, Office on Smoking and Health; 2020.

19. Siu AL, U.S. Preventive Services Task Force. Behavioral and pharmacotherapy interventions for tobacco smoking cessation in adults, including pregnant women: U.S. Preventive Services Task Force recommendation statement. Ann Intern Med. 2015;163(8):622-34. https://doi.org/10.7326/ M15-2023.

20. Lemhoefer C, Rabe GL, Wellmann J, Bernstein SL, Cheung KW, McCarthy WJ, et al. Emergency department-initiated tobacco control: update of a systematic review and meta-analysis of randomized controlled trials. Prev Chronic Dis. 2017;14:E89. https://doi.org/10.5888/pcd14.160434.

21. Rabe GL, Wellmann J, Bagos P, Busch MA, Hense H, Spies C, et al. Efficacy of emergency department-initiated tobacco control-systematic review and meta-analysis of randomized controlled trials. Nicotine Tob Res. 2013;15(3):643-55. https://doi.org/10.1093/ntr/nts212. 
22. Merianos AL, Gordon JS, Lyons MS, Jandarov RA, Mahabee-Gittens EM. Evaluation of tobacco screening and counseling in a large, midwestern pediatric emergency department. Tob Prev Cessat. 2021;7:39. https://doi. org/10.18332/tpc/134751.

23. Lustre BL, Dixon CA, Merianos AL, Gordon JS, Zhang B, Mahabee-Gittens EM. Assessment of tobacco smoke exposure in the pediatric emergency department. Prev Med. 2016;85:42-6. https://doi.org/10.1016/j.ypmed. 2016.01.003.

24. Mahabee-Gittens EM, Gordon JS. Missed opportunities to intervene with caregivers of young children highly exposed to secondhand tobacco smoke. Prev Med. 2014;69:304-5. https://doi.org/10.1016/j.ypmed.2014. 10.031 .

25. Mahabee-Gittens EM, Stone L, Gordon JS. Pediatric emergency department is a promising venue for adult tobacco cessation interventions. Nicotine Tob Res. 2013;15(10):1792-3.

26. Deckter L, Mahabee-Gittens EM, Gordon JS. Are pediatric emergency department nurses delivering tobacco cessation advice to parents? J Emerg Nurs. 2009;35(5):402-5. https://doi.org/10.1016/j.jen.2007.10.018.

27. Mahabee-Gittens EM, Gordon JS, Krugh ME, Henry B, Leonard AC. A smoking cessation intervention plus proactive quitline referral in the pediatric emergency department: a pilot study. Nicotine Tob Res. 2008;10(12):1745-51. https://doi.org/10.1080/14622200802443494.

28. Cane J, O'Connor D, Michie S. Validation of the theoretical domains framework for use in behaviour change and implementation research Implement Sci. 2012;7(1):37. https://doi.org/10.1186/1748-5908-7-37.

29. Michie S, Johnston M, Abraham C, Lawton R, Parker D, Walker A, et al. Making psychological theory useful for implementing evidence based practice: a consensus approach. Qual Saf Health Care. 2005;14(1):26-33. https://doi.org/10.1136/qshc.2004.011155.

30. Amemori M, Michie S, Korhonen T, Murtomaa H, Kinnunen TH. Assessing implementation difficulties in tobacco use prevention and cessation counselling among dental providers. Implement Sci. 2011;6(1):50. https:// doi.org/10.1186/1748-5908-6-50.

31. Atkins L, Francis J, Islam R, O'Connor D, Patey A, Ivers N, et al. A guide to using the Theoretical Domains Framework of behaviour change to investigate implementation problems. Implement Sci. 2017;12(1):77. https:// doi.org/10.1186/s13012-017-0605-9.

32. Boeckmann M, Warsi S, Noors M, Dogar O, Mustagfira EH, Firoze F, et al. Health worker and patient views on implementation of smoking cessation in routine tuberculosis care. NPJ Prim Care Respir Med. 2019;29(1):34-12. https://doi.org/10.1038/s41533-019-0146-6.

33. Bar-Zeev Y, Skelton E, Bonevski B, Gruppetta M, Gould GS. Overcoming challenges to treating tobacco use during pregnancy - a qualitative study of Australian general practitioners barriers. BMC Pregnancy Childbirth. 2019;19(1):61. https://doi.org/10.1186/s12884-019-2208-8.

34. Creswell JW, Creswell JW. Qualitative inquiry and research design: choosing among five approaches. Los Angeles: SAGE Publications; 2013.

35. Lipworth W, Taylor N, Braithwaite J. Can the theoretical domains framework account for the implementation of clinical quality interventions? BMC Health Serv Res. 2013;13(1):530. https://doi.org/10.1186/ 1472-6963-13-530.

36. Mahabee-Gittens EM, Dixon CA, Vaughn LM, Duma EM, Gordon JS. Parental tobacco screening and counseling in the pediatric emergency department: practitioners' attitudes, perceived barriers, and suggestions for implementation and maintenance. J Emerg Nurs. 2014;40(4):336-45. https://doi.org/10.1016/j.jen.2013.06.001.

37. Buchbinder M, Wilbur R, Zuskov D, McLean S, Sleath B. Teachable moments and missed opportunities for smoking cessation counseling in a hospital emergency department: a mixed-methods study of patientprovider communication. BMC Health Serv Res. 2014;14(1):651. https:// doi.org/10.1186/s12913-014-0651-9.

38. Walters EL, Reibling ET, Wilber ST, Sullivan AF, Gaeta TJ, Camargo CA, et al. Emergency department provider preferences related to clinical practice guidelines for tobacco cessation: a multicenter survey. Acad Emerg Med. 2014;21(7):785-93. https://doi.org/10.1111/acem.12421.

39. Vokes NI, Bailey JM, Rhodes KV. "Should I give you my smoking lecture now or later?" Characterizing emergency physician smoking discussions and cessation counseling. Ann Emerg Med. 2006;48(4):406-414.e1-7. https://doi.org/10.1016/j.annemergmed.2006.03.037.

40. Sheffer CE, Payne T, Ostroff JS, Jolicoeur D, Steinberg M, Czabafy S, et al. Increasing the quality and availability of evidence-based treatment for tobacco dependence through unified certification of tobacco treatment specialists. J Smok Cessat. 2016;11(4):229-35. https://doi.org/10.1017/jsc. 2014.30.

41. Centers for Disease Control and Prevention. Best Practices for Comprehensive Tobacco Control Programs-2014. Atlanta: U.S. Department of Health and Human Services, Centers for Disease Control and Prevention, National Center for Chronic Disease Prevention and Health Promotion, Office on Smoking and Health; 2014.

42. Rojewski AM, Bailey SR, Bernstein SL, Cooperman NA, Gritz ER, KaramHage MA, et al. Considering systemic barriers to treating tobacco use in clinical settings in the United States. Nicotine Tob Res. 2019;21(11):145361. https://doi.org/10.1093/ntr/nty123.

43. Lindson N, Thompson TP, Ferrey A, Lambert JD, Aveyard P, Lindson N. Motivational interviewing for smoking cessation. Cochrane Database Syst Rev. 2019;7(7):CD006936. https://doi.org/10.1002/14651858.CD006936. pub4.

44. Mahabee-Gittens EM, Matt GE, Hoh E, Quintana PJE, Stone L, Geraci MA, et al. Contribution of thirdhand smoke to overall tobacco smoke exposure in pediatric patients: study protocol. BMC Public Health. 2019;19(1):491. https://doi.org/10.1186/s12889-019-6829-7.

45. Thirdhand Smoke Resource Center: thirdhand smoke: what every primary care provider needs to know. https://thirdhandsmoke.org/resources/ webinars/ (2019). Accessed 7 Feb 2021.

46. Drehmer JE, Ossip DJ, Nabi-Burza E, Rigotti NA, Hipple B, Woo H, et al. Thirdhand smoke beliefs of parents. Pediatrics. 2014;133(4):e850-6. https://doi.org/10.1542/peds.2013-3392.

47. Mahabee-Gittens EM, Merianos AL, Jandarov RA, Quintana PJE, Hoh E, Matt GE. Differential associations of hand nicotine and urinary cotinine with children's exposure to tobacco smoke and clinical outcomes. Environ Res. 2021;202:111722. https://doi.org/10.1016/j.envres.2021.111722.

48. Mahabee-Gittens EM, Merianos AL, Matt GE. Preliminary evidence that high levels of nicotine on children's hands may contribute to overall tobacco smoke exposure. Tob Control. 2018;27(2):217-9. https://doi.org/ 10.1136/tobaccocontrol-2016-053602.

49. Katz DA, Paez MW, Reisinger HS, Gillette MT, Weg MW, Titler MG, et al. Implementation of smoking cessation guidelines in the emergency department: a qualitative study of staff perceptions. Addict Sci Clin Pract. 2014;9(1):1. https://doi.org/10.1186/1940-0640-9-1.

50. Farber HJ, Walley SC, Groner JA, Nelson KE. Section on Tobacco Control. Clinical practice policy to protect children from tobacco, nicotine, and tobacco smoke. Pediatrics. 2015;136(5):1008-17. https://doi.org/10.1542/ peds.2015-3108.

51. Mahabee-Gittens EM, Dexheimer JW, Tabangin M, Khoury JC, Merianos AL, Stone L, et al. An Electronic Health Record-Based Strategy to Address Child Tobacco Smoke Exposure. Am J Prev Med. 2018;54(1):64-71. https://doi.org/10.1016/j.amepre.2017.08.011.

52. Cunningham RM, Bernstein SL, Walton M, Broderick K, Vaca FE, Woolard $\mathrm{R}$, et al. Alcohol, tobacco, and other drugs: future directions for screening and intervention in the emergency department. Acad Emerg Med. 2009;16(11):1078-88. https://doi.org/10.1111/j.1553-2712.2009.00552.x.

53. Prochazka A, Koziol-McLain J, Tomlinson D, Lowenstein SR. Smoking cessation counseling by emergency physicians: opinions, knowledge, and training needs. Acad Emerg Med. 1995;2(3):211-6. https://doi.org/10. 1111/j.1553-2712.1995.tb03201.x.

54. Barbosa C, McKnight-Eily LR, Grosse SD, Bray J. Alcohol screening and brief intervention in emergency departments: review of the impact on healthcare costs and utilization. J Subst Abus Treat. 2020;117:108096. https://doi.org/10.1016/j.jsat.2020.108096.

55. Pringle JL, Kelley DK, Kearney SM, Aldridge A, Dowd W, Johnjulio W, et al. Screening, brief intervention, and referral to treatment in the emergency department: an examination of health care utilization and costs. Med Care. 2018;56(2):146-52. https://doi.org/10.1097/MLR.0000000000 000859.

56. Mahabee-Gittens EM, Ammerman RT, Khoury JC, Tabangin ME, Ding $L$, Merianos $A L$, et al. A parental smoking cessation intervention in the pediatric emergency setting: a randomized trial. Int J Environ Res Public Health. 2020;17(21):8151. https://doi.org/10.3390/ijerph17218151.

57. Li WHC, Ho KY, Wang MP, Cheung DYT, Lam KKW, Xia W, et al. Effectiveness of a brief self-determination theory-based smoking cessation intervention for smokers at emergency departments in Hong Kong: a 
randomized clinical trial. JAMA Intern Med. 2019;180(2):206-14. https:// doi.org/10.1001/jamainternmed.2019.5176.

58. Tindle HA, Daigh R, Reddy VK, Bailey LA, Ochs JA, Maness MH, et al. eReferral between hospitals and quitlines: an emerging tobacco control strategy. Am J Prev Med. 2016;51(4):522-6. https://doi.org/10.1016/j. amepre.2016.05.024.

59. McCall MH, Wester KL, Bray JW, Hanchate AD, Veach LJ, Smart BD, et al. SBIRT administered by mental health counselors for hospitalized adults with substance misuse or disordered use: evaluating hospital utilization and costs. J Subst Abus Treat. 2021;132:108510. https://doi.org/10.1016/j. jsat.2021.108510.

60. Boudreaux ED, Abar B, Haskins B, Bauman B, Grissom G. Health evaluation and referral assistant: a randomized controlled trial to improve smoking cessation among emergency department patients. Addict Sci Clin Pract. 2015;10:24. https://doi.org/10.1186/s13722-015-0045-2.

61. Merianos AL, Jandarov RA, Gordon JS, Lyons MS, Mahabee-Gittens EM. Child tobacco smoke exposure and healthcare resource utilization patterns. Pediatr Res. 2020;88(4):571-9. https://doi.org/10.1038/ s41390-020-0997-0.

62. Merianos AL, Jandarov RA, Gordon JS, Lyons MS, Mahabee-Gittens EM. Healthcare resources attributable to child tobacco smoke exposure. PLoS One. 2021;16(2):e0247179. https://doi.org/10.1371/journal.pone.0247179.

63. Merianos AL, Jandarov RA, Mahabee-Gittens EM. High cotinine and healthcare utilization disparities among low-income children. Am J Prev Med. 2021;60(2):267-75. https://doi.org/10.1016/j.amepre.2020.06.018.

64. National Center for Chronic Disease Prevention and Health Promotion Office on Smoking and Health. Preventing tobacco use among youth and young adults: a report of the Surgeon General. Atlanta: Centers for Disease Control and Prevention; 2012.

\section{Publisher's Note}

Springer Nature remains neutral with regard to jurisdictional claims in published maps and institutional affiliations.

- fast, convenient online submission

- thorough peer review by experienced researchers in your field

- rapid publication on acceptance

- support for research data, including large and complex data types

- gold Open Access which fosters wider collaboration and increased citations

- maximum visibility for your research: over $100 \mathrm{M}$ website views per year

At BMC, research is always in progress.

Learn more biomedcentral.com/submissions 